\title{
創造果樹新品種 繁殖果樹的新方法
}

\section{介紹平原省林縣老農石玉殿}

\section{奇異的果楖林}

平原省林縣一帶,一片山丘沙灘, 祇有、答落的 荟翠的樹水。可是, 如果你到東冶村一帶, 那裹却 是綠樹成落, 你會在樹林異發現許多使人㢣異的 奇蹟：一棵林樹，結着五種大小、硬軟、味道不同的 柿子。分明是一柦柳樹根，却長着杏、桃、栗等各種

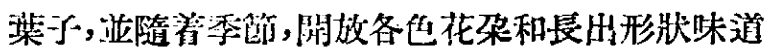
不闹的果子。

是譙創造這陭異的果樹林？是一倜普通的莊

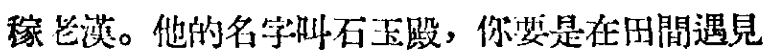
他, 他會滔滔不絕地和你满解許多改造果樹的故 事。

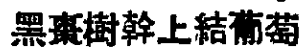

石玉殿已經接了四十三年樹。十四歲時,他給 地主放牛, 就已向鄰居老漢學會了接樹。以後, 年 年替别人接樹。二十一歲時, 他看見花匠把兩棵果 樹制了二段吱,接在一起,用泥和芶草包紮好,第二

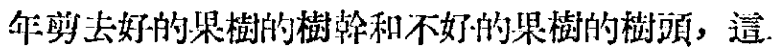
樣就能改進果于的品签。他也用這犁方法, 把柿一个 樹和黑资樹接起來，第二年，結的柿子又大又好。

有一次, 他異想天阴地把蒱萄的樹翰扯到黑

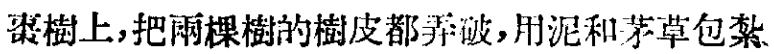

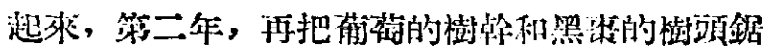
斷, 秋天把茠萄摘下來吃, 爅! 全都沒核啦。後來他 又試把蔽得科培多樹木接起來, 結果都能長出果

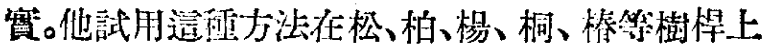
接柿子樹, 也可以結成果搳, 只是味道不好吃。

他創造了多听接水改進棵實的方法。蘋果接

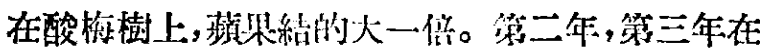
已接木的蘋果桿上侢接, 蘋果就綃的更大了。花紅 (莎果)桿上接水·接了一次, 只是結一年,歇一年; 接了兩次,就能年年結着又大又稠的荣子。桃樹接

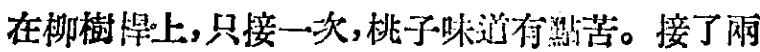
次, 就㚲美可口了。

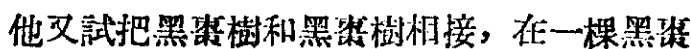

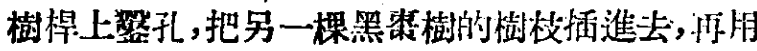

泥土糊上，用茅草包焚好，第二年，長出沒核的黑 呆來!

\section{新接樹法}

熟能生巧,他又創造了新的接樹方法。

第一種方法是插枝”,郎把黑象樹桿鋸斷, 用

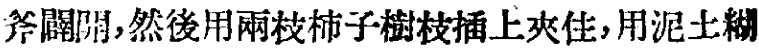
上,不用茅草縓也能活了。

第二種方法是 “扣皮”，郎把柿子的樹皮剩下

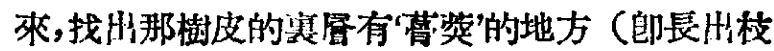
芽處，用刀切壮一塊，㷰在植樹人口裹。另外在黑 整樹桿上劃去同樣大小的一塊樹皮，然後用缡在 口䍗的柿子樹皮㙋上去用茅草緊緊地綢徒, 再砍 斷黙赖的樹頍“扣皮”處就長出新芽來了。第一次“扣

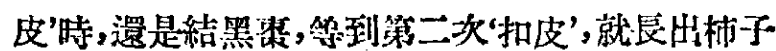
來了。這樣接木方法. 可以廣泛應用在詐多樹木 上。

他還深入地研究在什麼第楊，用什寉接樹方 法,能接什麼樣的樹。

\section{造林新法}

他摸索出了用厘枝法來繁殖樹木。在川地榬 梢挨近上遥梯田地方，用是枝方法(如朵這果樹是 經過接枝的,在上面梯田經過熶枝生根成長,就不 用再接木了。)美留的果樹便随着梯田的地等，‥ 展居往上繁殖起來。

在平地上,如用花兺或破鍋放上泥上,束在樹 上,也同樣可以長壮新樹，並可挪到其他地方去矩 植。(這一般叫做高愿枝。)

\section{㹂治果樹的䧼座症}

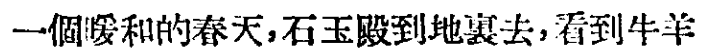

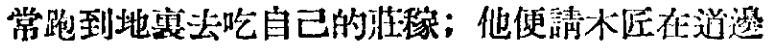

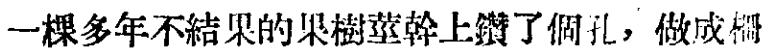

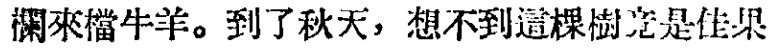

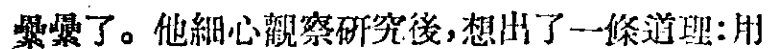

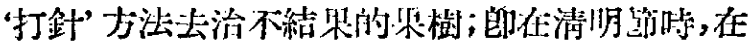

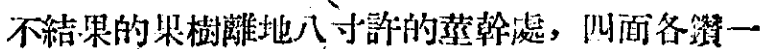
個兩三寸深的哏。如果一株果樹上准一校不絈喿, 
也可以探用運方法在枝上打幾針，賞年就可以結 果了。他還有品的治果樹不結果的良方: 如以地 的柿樹不結了, 就在樹根题刨誠坑; 蘋果樹不結 了, 就用小刀把樹皮切破; 花极不結了, 就把樹幹 的毛枝剪去。祀在去年他就治好了不結果的果樹

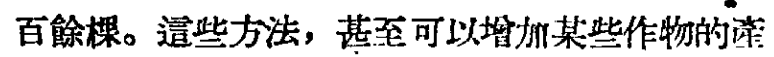

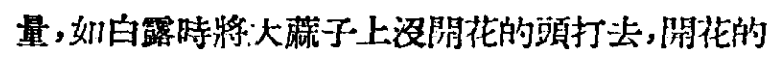
扒去兩旁小芽,去掉桿下傻的毛腿,這樣就能使藏 子結望飽滿。

\section{不保守接榯技術}

石玉殷的一生,和樹术結了不可解的因䊏。只 要别人願意, 他就肯白花工夫去幫助。四十三年 來, 他共給本村和鄰村接樹网萬多棵。他從來不保 守自己接尌的“秘訣”, 經常不斷地把接樹技術教給 别人, 祀在本村就已教會了四百多人。在外村二十
里內,到處傳授,說不清教會了多少人。

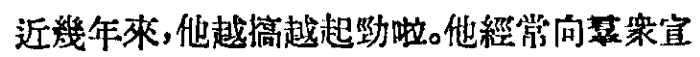
傅:“汥果樹的荒年挨餓,有果樹的年年吃跑。' ‘程 果樹利大。' ‘水大沲了莊稼, 流不了樹。'在他帶副 領尊下, 東冶村前年裁樹后千多棵, 去年三千多 棵，今年九千多橗，現在家家都有苗围。

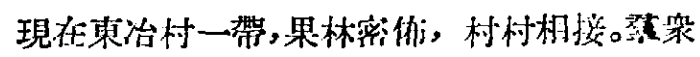
的收入堆加了,光景一天比一天强。他們一提戈石

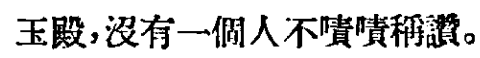

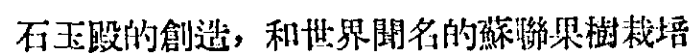
改革家的米邱林極相近似。研究和推廣這位優秀 的人民天才改良果术的經驗, 是一件很重慗的事 情。

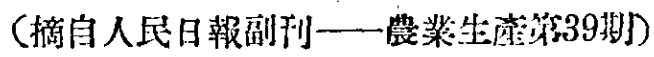

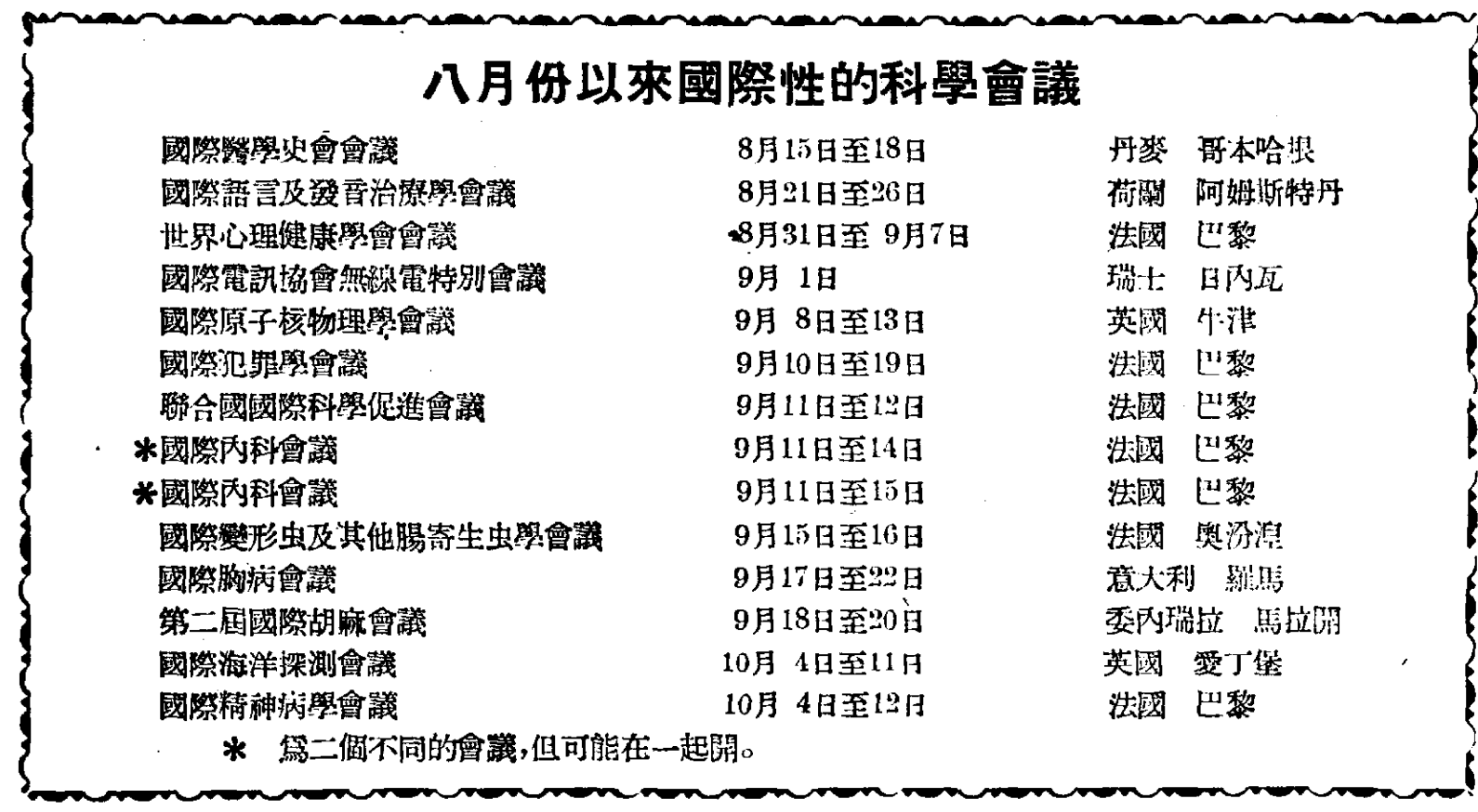

\section{更正}

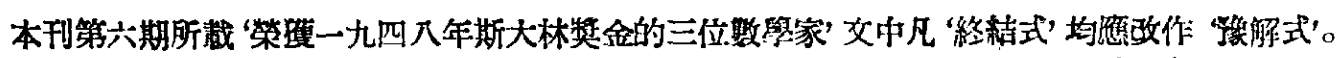

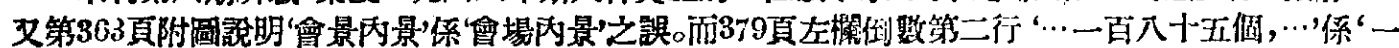

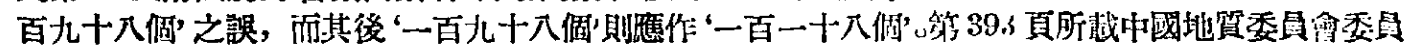

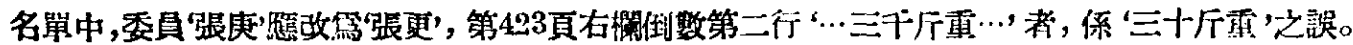
予取消。

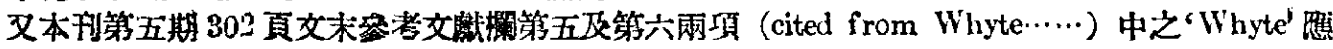

